\title{
Meningkatkan Pengetahuan, Minat dan Bakat Peserta Didik terhadap Seni Tari dengan Model Pembelajaran Explicit Intruction di SMK Negeri 7 Kota Bandung
}

\section{Improve Students Knowledge, Interests and Talents of Dance with the Explicit Intruction Learning Model at SMKN Negeri 7 in Bandung}

\author{
Yuniar Farita Hermawati \\ SMK Negeri 7 Bandung, Bandung, Jawa Barat, Indonesia \\ yuniarfarita2@gmail.com
}

Naskah diterima tanggal 14/08/2019, direvisi akhir tanggal 05/12/2019, disetujui tanggal 11/12/2019

\begin{abstract}
Abstrak
Perkembangan pendidikan tentunya berpengaruh terhadap kehidupan global yang dapat melatih sumber daya manusia agar lebih kompetitif dan inovatif. Untuk memiliki sumber daya tersebut, maka komponen-komponen pembelajaran yang bekerja didalamnya pun harus lebih ditingkatkan. Seni Budaya merupakan salah satu materi pembelajaran yang terdapat di sekolah, dalam pembelajaran Seni Budaya salah satunya terdapat kompetensi dasar mengenai Seni Tari. Dalam proses pembelajaran ini perlu adanya pendekatan mengenai minat dan bakat yang dimiliki oleh peserta didik dengan metode pembelajaran explicit instruction. Tujuan penelitian ini untuk meningkatkan hasil belajar, motivasi, dan keterampilan dalam mengekspresikan Seni Tari melalui model pembelajaran yang lebih baik. Metode penelitian yang digunakan adalah dengan pendekatan kuantitatif dan kualitatif. Subjek dalam penelitian ini adalah siswa dan siswi kelas X-F1 SMK Negeri 7 Kota Bandung tahun ajaran 2017/2018 yang berjumlah 31 orang. Hasil penelitian menunjukkan bahwa dengan metode pembelajaran explicit instruction, hasil prestasi belajar siswa kelas X-F1SMK Negeri 7 Kota Bandung tahun ajaran 2017/2018 dalam tari kreasi baik individu maupun kelompok terdapat peningkatan. Secara individu dan kelompok, siswa memperoleh rata-rata kriteria baik dan sangat baik. Disarankan bagi guru dapat meningkatkan kinerjanya sebagai guru seni budaya dalam pembelajaran seni tari, dengan mengoptimalkan peran guru sebagai mediator, fasilitator, narasumber dan pembimbing bagi siswa. Diharapkan dengan adanya metode pembelajaran explicit instruction dapat meningkatkan motivasi belajar siswa sebagai upaya mengembangkan seni budaya, khususnya tarian nusantara.
\end{abstract}

Kata Kunci: explicit instruction, kualitatif, kuantitatif, model pembelajaran, seni tari.

\begin{abstract}
Educational development certainly affects the global life that can train human resources to be more competitive and innovative. To have these resources, the learning components that work within must also be further improved. Art and Culture is one of the learning materials that are available in school, one of them is the basic competence in learniung about Dance. In this learning process there needs to be an approach regarding the interests and talents prossessed by students with the Explicit Intruction learning method. The purpose of this study is to improve learning outcomes, motivation and skills in expressing Dance through better learning models. The research method used is a quantitative and qualitative approach. The subjects in this study werw students of class X-F1 of SMKN 7 Bandung in academic yaer 2017/2018, amounting to 31 people. The results showed that with the Explicit Intruction learning method, the results of class X-F1 students achievement in SMKN 7 Bandung academic year 2017/2018 in Dance Creations both individuals and groups there was an increase. Individually and in groups of
\end{abstract}


students obtain good and very good criteria. It is recommended for teachers to improve their performance as arts and culture teachers in learning Dance, by optimizing the role of teachers as mediators, facilitators, resource persons and mentors for students. It is expected that the existence of Explicit Intruction learning methods can increase student motivation as an effort to develop cultural arts, especially the archipelago dance.

Keywords: dance, explicit intruction, learning models, qualitative, quantitative.

\section{PENDAHULUAN}

Pendidikan memegang peranan penting dalam mempersiapkan sumber daya manusia bagi kehidupan di masa yang akan datang dikarenakan pendidikan merupakan salah satu indikator dalam menentukan indeks pembangunan manusia di suatu negara. Di Indonesia pendidikan telah mengalami perkembangan dari waktu ke waktu dalam segala aspek pembelajaran mulai dari sarana, fasilitas, media pembelajaran, teknologi pendidikan dan tenaga pengajar. Perkembangan pendidikan tentunya berpengaruh terhadap kehidupan global yang dapat melatih sumber daya manusia agar lebih kompetitif dan inovatif.

Untuk memiliki sumber daya yang lebihkompetitifdan inovatifmaka komponenkomponen pembelajaran yang bekerja didalamnya pun harus lebih ditingkatkan. Komponen dalam pembelajaran dapat berupa tujuan, bahan pelajaran, kegiatan belajar mengajar, metode, alat, sumber pelajaran, dan evaluasi (Djamarah \& Zain, 2013:41). Dengan demikian kualitas pengajaran dan pembelajaran akan lebih baik.

Seni meliputi penciptaan dari segala hal atau benda yang karena keindahan bentuknya sehingga orang senang melihatnya atau mendengarnya. Dengan demikian seni atau kesenian adalah ekspresi gagasan atau perasaan manusia yang diwujudkan melalui pola kelakuan yang menghasilkan karya yang bersifat estetis dan bermakna (Ali, 2007:915).

Pendidikan Seni Tari diberikan di sekolah karena keunikan, kebermaknaan, dan kebermanfaatan terhadap kebutuhan dan berapresiasi melalui pendekatan "belajar dengan seni", "belajar melalui seni", dan "belajar tentang seni". Seni Budaya merupakan salah satu materi pembelajaran yang terdapat di sekolah, dalam pembelajaran Seni Budaya salah satunya terdapat kompetensi dasar mengenai Seni Tari, begitupun di SMK Negeri 1 Kota Bandung.

Akan tetapi ekspresi seni manusia sangatlah beragam, dikarenakan ekspresi seni itu sendiri timbul dengan berbagai gagasan, bentuk dan corak ungkapannya. Keragaman ekspresi seni ini berkembang sesuai dengan pengaruh kebudayaan masyarakat, kepercayaan, perbedaan kondisi sosial, lingkungan alam sekitar, dan juga memungkinkan karena adanya perkembangan kemajuan teknologi. Dengan demikian perlu adanya pendekatan terhadap siswa mengenai minat dan bakat yang dimiliki oleh peserta didik.

Model explicit intruction (pengajaran langsung) didefinisikan sebagai salah satu pendekatan mengajar yang dirancang khusus untuk menunjang proses belajar siswa yang berkaitan dengan pengetahuan deklaratif dan pengetahuan prosedural yang terstruktur dengan baik yang dapat diajarkan dengan pola kegiatan yang bertahap, selangkah demi selangkah (Arends, Winitzky, \& Tannenbaum, 2001:264). Model explicit intruction dikatakan sebagai salah satu model pembelajaran yang menekankan pada pendekatan guru dan siswa secara personal sehingga siswa dapat lebih mengerti tentang materi yang diajarkan dengan adanya bimbingan dari guru. Hal ini dapat lebih mendekatkan siswa dengan guru secara intern sehingga siswa tidak malu lagi dalam bertanya tentang hal yang belum mereka pahami (Yudha, Arsa, \& Sutaya, 2014:3). Sedangkan menurut Kardi (dalam Huda (2013:186) model explicit intruction, dapat berbentuk ceramah, demonstrasi, pelatihan 
atau praktik, dan kerja kelompok yang digunakan untuk menyampaikan pelajaran yang ditransformasikan langsung oleh guru kepada siswa.

Explicit instruction merupakan salah satu model pembelajaran yang memiliki lima langkah yang diantaranya adalah guru menyampaikan tujuan pembelajaran kepada murid, mendemonstrasikan pengetahuan dan keterampilan, membimbing murid dalam pelatihan, mengecek pemahaman murid, dan memberikan kesempatan kepada murid untuk latihan lanjutan. Peneliti selaku guru kesenian juga mencoba menggunakan strategi mengajar yang tepat yaitu dengan penerapan seni tradisional maupun modern.

Suprijono (2010:130) menyatakan bahwa ada beberapa tahapan atau langkah dalam pengajaran langsung (Explicit Intruction), meliputi:

a. menyampaikan tujuan dan mempersiapkan siswa,

b. mendemontrasikan pengeatahuan dan keterampilan,

c. membimbing pelatihan,

d. mengecek pemahaman dan memberikan umpan balik, dan

e. memberikan kesempatan untuk latihan lanjutan.

Sedangkan langkah-langkah pembelajaran model explicit instruction menurut Huda (2013:187) adalah:

a. Tahap 1: Orientasi

Guru menjelaskan TPK, informasi latar belakang pelajaran, pentingnya pelajaran, dan mempersiapkan siswa untuk belajar.

b. Tahap 2: Presentasi

Guru mendemontrasikan materi pelajaran, baik berupa keterampilan maupun konsep atau menyajikan informasi tahap demi tahap.

c. Tahap 3: Latihan Terstruktur

Guru merencanakan dan memberikan bimbingan intruksi awal kepada siswa.

d. Tahap 4: Latihan Terbimbing

Guru memeriksa apakah siswa telah berhasil melaksanakan tugas dengan baik dengan memberinya kesempatan untuk berlatih konsep dan keterampilan, lalu melihat apakah mereka berhasil memberi umpan balik yang positif atau tidak.

e. Tahapan 5: Latihan Mandiri

Guru merencanakan kesempatan untuk melakukan intruksi lebih lanjut dengan berfokus pada situasi yang lebih kompleks atau kehidupan sehari-hari.

Menurut Qirana, dkk (dalam Khoiriyah, 2015) mengemukakan bahwa ada beberapa langkah-langkah pembelajaran model explicit instruction adalah:

a. guru menyampaikan tujuan dan mempersiapkan siswa

b. guru mendemonstrasikan materi

c. guru membimbing murid dalam pelatihan

d. guru memberikan umpan balik; serta

e. pelatihan mandiri.

Kardi (dalam Huda, 2013:187-188) mengungkapkan model pembelajaran explicit instruction memiliki kelebihan dan kelemahan. Kelebihan model pembelajaran explicit instruction, diantaranya:

a. Guru bisa mengendalikan isi materi dan urutan informasi yang diterima oleh siswa sehingga guru dapat mempertahankan fokus apa yang harus dicapai oleh siswa.

b. Dapat diterapkan secara efektif dalam kelas yang besar maupun kecil.

c. Dapat digunakan untuk menekankan poin-poin penting atau kesulitan-kesulitan yang mungkin dihadapi siswa sehingga hal-hal tersebut dapat diungkapkan.

d. Dapat menjadi cara yang efektif untuk mengajarkan informasidan pengetahuan faktual yang sangat terstruktur.

e. Merupakan cara yang paling efektif untuk mengajarkan konsep dan keterampilanketerampilan yang eksplisit kepada siswa yang berprestasi rendah.

f. Dapat menjadi cara untuk menyampaikan informasi yang banyak dalam waktu yang relative singkat dan dapat diakses secara setara oleh seluruh siswa.

g. Memungkinkan guru untuk menyampaikan ketertarikan pribadi mengenai mata pelajaran (melalui presentasi yang antusias) yang dapat merangsang ketertarikan dan antusiasme siswa.

Sedangkan kelemahan dari model pembelajaran explicit instruction, yaitu :

a. Terlalu bersandar pada kemampuan siswa 
untuk mengasimilikasikan informasi melalui kegiatan mendengarkan, mengamati, dan mencatat, sementara tidak semua siswa memiliki keterampilan dalam hal-hal tersebut, sehingga guru masih harus mengajarkannya kepada siswa.

b. Kesulitan untuk mengatasi perbedaan dalam hal kemampuan, pengetahuan awal, tingkat pembelajaran dan pemahaman, gaya belajar, atau ketertarikan siswa.

Dengan adanya berbagai hasil penelitian yang menyebutkan bahwa tingkat struktur dan kendali guru yang tinggi dalam kegiatan pembelajaran, yang menjadi karakteristik strategi explicit instruction, dapat berdampak negatif terhadap kemampuan penyelesaian masalah, kemandirian, keingintahuan siswa.

Tema penelitian mengenai model pembelajaran explicit instruction telah banyak digunakan dengan pengaplikasian pada beberapa bidang yang berbeda diantaranya adalah penelitian yang dilakukan oleh Maulidar (2016); Megawati (2016); Primadani (2011); Silma (2017); Suroto (2015); Amsa (2018); Anwar \& Lapenia (2019); Fatimah, Wartiningsih, \& Istiandini (2014); Handayani (2018); Khoiriyah (2015); Lutfiiyah \& Mansur (2018); Nurvitriawati \& Sulfasyah (2018); Oktarina (2017); Ratunguri \& Jane (2016); Utari, Parmiti, \& Sudana (2016).

Dari adanya keberagaman ekspesi, dan ditanjau dari perbedaan minat dan bakat setiap siswa maka dengan demikian dirasa perlu melakukan penelitian dengan judul "Meningkatkan Pengetahuan, Minat dan Bakat Peserta Didik Terhadap Seni Tari dengan Model Pembelajaran Explicit Intruction di SMK Negeri 7 Kota Bandung”.

\section{METODE PENELITIAN}

Tujuan penelitian ini untuk meningkatkan hasil belajar, motivasi, dan keterampilan dalam mengekspresikan Seni Tari melalui model pembelajaran yang lebih baik. Metode penelitian yang digunakan adalah dengan pendekatan kuantitatif dan kualitatif dengan model pembelajaran explicit instruction yang diterapkan pada sub kompetensi memahami konsep, teknik dan prosedur dalam menirukan ragam gerak dasar tari. Subjek dalam penelitian ini adalah siswa dan siswi kelas X-F1 SMK Negeri 7 Kota Bandung tahun ajaran 2017/2018 yang berjumlah 31 orang.

\section{HASIL DAN PEMBAHASAN \\ 3.1 Hasil}

\section{Persiapan Tindakan I}

Persiapan yang dilakukan untuk melaksanakan tindakan I adalah penyusunan rencana pembelajaran tindakan I, pedoman observasi untuk membantu dalam menentukan aktifitas belajar siswa. Proses pembelajaran ini dikuti oleh 31 siswa dari seluruh siswa kelas X-F1 SMK Negeri 7 Bandung sub kompetensi yang dibahas pada tindakan I adalah Memahami konsep, teknik dan prosedur dalam menirukan ragam gerak dasar tari

\section{Pelaksanaan Tindakan I}

Pada tahap tindakan ini, menekankan implementasi terhadap proses pembelajaran sesuai dengan rencana yang telah ditetapkan sebagai berikut:

a. Kegiatan Pendahuluan

1) Kesiapan alat bantu media pembelajaran

2) Mengkondisikan siswa

3) Memberikan apersepsi dan motivasi

4) Penjelasan tujuan dan materi pembelajaran

5) Mendemonstrasikan pengetahuan dan keterampilan tarian kelompok nusantara

b. Kegiatan Pokok

1) Penguasan materi dan urutan penyajian.

2) Penggunaan metode dan pendekatan pembelajaran.

3) Penggunaan alat peraga atau alat bantu pelajaran.

4) Bimbingan kepada siswa, peran guru sebagai fasilitator.

5) Teknik bertanya dan keterampilan berkomunikasi dengan siswa.

6) Interaksi guru dengan siswa sebagai peserta didik. 
7) Membantu dan membimbing siswa dalam praktek atau berlatih tari.

8) Aktivitas dan kreativitas siswa dalam kelompok tari.

9) Pemecahan kesulitan siswa dalam belajar tarian kelompok

10)Menghubungkan materi pelajaran dengan ahlak/ budi pekerti, teknologi, dan kehidupan sehari-hari.

11) Menyimpulkan materi pelajaran.

c. Kegiatan Penutup

1) Praktek menari kreasi tarian kelompok nusantara

2) Pemberian tugas lanjutan

Tabel 1.

Hasil Observasi Kinerja Siswa dalam Pembelajaran Tarian Kelompok

\begin{tabular}{|c|c|c|c|c|c|c|c|}
\hline \multirow{2}{*}{ No. } & \multirow{2}{*}{ Aspek-aspek yang diobservasi } & \multicolumn{5}{|c|}{ Penilaian } & \multirow{2}{*}{ Ket. } \\
\hline & & SB & $\mathbf{B}$ & $\mathbf{C}$ & $\mathbf{K}$ & SK & \\
\hline \multirow[t]{5}{*}{1.} & Perhatian siswa dalam KBM & & & & & & \\
\hline & a. Siswa duduk dengan tertib dan tenang. & & $\mathrm{V}$ & & & & \\
\hline & b. Siswa menjawab salam dan guru. & & $\mathrm{V}$ & & & & \\
\hline & $\begin{array}{l}\text { c. Siswa memperhatikan penjelasan guru tentang tujuan } \\
\text { pembelajaran dan materi tari kreasi kelompok. }\end{array}$ & & $\mathrm{V}$ & & & & \\
\hline & $\begin{array}{l}\text { d. Siswa memperhatikan demonstrasi guru tentang contoh } \\
\text { gerakan tari kreasi. }\end{array}$ & $\mathrm{V}$ & & & & & \\
\hline \multirow[t]{5}{*}{2.} & $\begin{array}{l}\text { Kesungguhan siswa mengajukan pertanyaan atau memberi } \\
\text { tanggapan terhadap materi pelajaran. }\end{array}$ & & & & & & \\
\hline & a. Pertanyaan siswa sesuai materi pelajaran. & & $\mathrm{V}$ & & & & \\
\hline & b. Jumlah siswa yang bertanya tentang materi pelajaran. & & $\mathrm{V}$ & & & & \\
\hline & $\begin{array}{l}\text { c. Komentar atau tanggapan siswa terhadap demonstrasi } \\
\text { guru dalam contoh menari tarian kelompok. }\end{array}$ & $\mathrm{V}$ & & & & & \\
\hline & $\begin{array}{l}\text { d. Tanggapan siswa terhadap pertanyaan dan teman } \\
\text { tentang materi pembelajaran (memberi umpan balik). }\end{array}$ & & $\mathrm{V}$ & & & & \\
\hline \multirow[t]{5}{*}{3.} & Keberanian siswa untuk menari tarian kelompok. & & & & & & \\
\hline & a. Memiliki motivasi dan kemauan untuk menari. & & $\mathrm{V}$ & & & & \\
\hline & $\begin{array}{l}\text { b. Melakukan contoh gerakan tari kreasi nusantara di } \\
\text { depan kelas. }\end{array}$ & & $\mathrm{V}$ & & & & \\
\hline & c. Berlatih menari tari kreasi kelompok. & $\mathrm{V}$ & & & & & \\
\hline & d. Menampilkan tari kreasi kelompok. & & $\mathrm{V}$ & & & & \\
\hline \multirow[t]{5}{*}{4.} & $\begin{array}{l}\text { Kesulitan siswa dalam menari tarian kreasi kelompok } \\
\text { melalui penerapan gerak-gerak dasar tari tradisional. }\end{array}$ & & & & & & \\
\hline & a. Unsur gerakan tubuh (wiraga) & & $\mathrm{V}$ & & & & \\
\hline & b. Unsur musik pengiring (wirahma) & & $\mathrm{V}$ & & & & \\
\hline & c. Unsur penjiwaan (wirasa) & & $\mathrm{V}$ & & & & \\
\hline & d. Unsur penyajian / pola lantai tari kelompok. & & $\mathrm{V}$ & & & & \\
\hline \multirow[t]{4}{*}{5.} & Kemampuan siswa dalam menari tarian kelompok. & & & & & & \\
\hline & a. Unsur penjiwaan (wirasa) & & $\mathrm{V}$ & & & & \\
\hline & b. Unsur irama /musik pengiring . (wirahma). & & $\mathrm{V}$ & & & & \\
\hline & c. Unsur ekspresi / penjiwaan (wirasa). & & $\mathrm{V}$ & & & & \\
\hline
\end{tabular}

Dengan Keterangan :

$\mathrm{SB}=$ Sangat Baik

$\mathrm{B}=$ Baik

$\mathrm{C} \quad=$ Cukup

$\mathrm{K}=$ Kurang

SK = Sangat Kurang

\subsection{Hasil Pembahasan}

Data dari hasil tabel Hasil Observasi
Kinerja Siswa dalam Pembelajaran Tarian

Kelompok, dapat diketahui bahwa kinerja 
siswa dalam pembelajaran Tarian Kelompok memberikan nilai rata-rata baik. Hal ini dikarenakan siswa secara individu maupun kelompok sudah mengerti, memahami, dan mempraktekkan pengetahuan dan keterampilan TarianKelompokyangdiberikan guru melalui proses pembimbingan. Maka secara individu dan kelompok, pembelajaran ini dinilai berhasil dan tuntas.

Dengan adanya temuan kuantitatif pada penelitian tindakan kelas yang telah dilakukan, maka diperoleh pula temuan kualitatif sebagai berikut:

a. Perhatian siswa terhadap pembelajaran tarian kelompok nusantara baik. Hal ini ditandai dengan perhatian yang serius oleh siswa terhadap penjelasan tujuan, materi dan demonstrasi tentang tari kreasi kelompok oleh guru dalam pembelajaran.

b. Kesungguhan siswa mengajukan pertanyaan dan memberi tanggapan atau komentar tentang pembelajaran tarian kelompok nusantara, semakin baik. Hal ini ditandai dengan meningkatnya pertanyaan siswa yang sesuai dengan materi, banyaknya komentar atau tanggapan siswa terhadap demonstrasi tarian kreasi kelompok nusantara oleh guru dan siswa lain, serta respon dan umpan balik yang tepat terhadap pertanyaan dan tanggapan tentang tari kreasi kelompok dari sesama siswa.

c. Keberanian siswa dalam menari tarian kreasi kelompok nusantara baik. Ini terpicu oleh kerjasama yang baik serta persaingan yang sehat antar kelompok tari. Motivasi menari semakin baik, kekompakan dalam berlatih dan menampilkan tarian kreasi nusantara berkelompok semakin baik hasilnya.

\section{KESIMPULAN}

Berdasarkan hasil dan pembahasan dalam penelitian ini, dapat ditarik beberapa kesimpulan penting, diantaranya :

\section{Hasil Penelitian Kuantitatif}

a. Hasil belajar seluruh siswa kelas X-F1 semester 1 tahun ajaran 2017/2018 di SMK Negeri 7 Kota Bandung sesuai dengan kriteria indikator keberhasilan siswa yang peneliti tetapkan, maka ratarata nilai kelas X-F1 semester 1 tahun ajaran 2017/2018 di SMK Negeri 7 Kota Bandung terdapat pada indikator baik yaitu 84,09. Tingkat keberhasilan siswa dalam pembelajaran dengan rata-rata nilai kelas pada indikator baik yaitu 75 85.

b. Hasil belajar seluruh siswa kelas X-F1 semester 2 tahun ajaran 2017/2018 di SMK Negeri 7 Kota Bandung sesuai dengan kriteria indikator keberhasilan siswa yang peneliti tetapkan, maka ratarata nilai kelas X-F1 semester 1 tahun ajaran 2017/2018 di SMK Negeri 7 Kota Bandung terdapat pada indikator sangat baik yaitu 85,47 . Tingkat keberhasilan siswa dalam pembelajaran dengan ratarata nilai kelas pada indikator baik yaitu diatas 85.

c. Dari hasil penelitian semester 1 dan 2 kelas X-F1 tahun ajaran 2017/2018 di SMK Negeri 7 Kota Bandung, terdapat 10 orang mengalami nilai rata-rata menurun, 3 orang mengalami nilai rata-rata tetap, dan sebagian besar yaitu 18 orang mengalami nilai rata-rata meningkat. Data hasil pembelajaran tarian di atas, menunjukan nilai rata-rata individu pada semester 1 dikategori baik dan semester 2 kategori sangat baik. Berdasarkan kriteria keberhasilan siswa secara individu yang peneliti tetapkan, maka nilai di atas 75 dinyatakan tuntas.

\section{Hasil Data Kualitatif}

a. Kinerja siswa dalam pembelajaran tarian memberikan nilai rata-rata sangat baik. Hal ini dikarenakan siswa secara individu maupun kelompok sudah mengerti, memahami, dan mempraktekkan pengetahuan dan keterampilan tarian yang diberikan guru melalui proses pembimbingan. Maka secara individu dan kelompok, pembelajaran ini dinilai berhasil dan tuntas.

b. Adanya perhatian siswa dalam pembelajaran tarian kelompok yang 
ditandai dengan ketertiban dan keseriusan siswa untuk memperhatikan dengan baik penjelasan guru tentang tujuan, materi pembelajaran, serta demonstrasi contoh tarian kreasi kelompok nusantara dinilai baik.

c. Adanya kesungguhan dan aktivitas siswa dalam memberikan tanggapan atau komentar serta umpan balik terhadap materi pembelajaran tari. Jumlah siswa yang mengajukan pertanyaan sesuai dengan materi, juga baik. d. Adanya keberanian dan kemampuan siswa untuk menari tarian kreasi nusantara, yang ditandai dengan motivasi menari serta aktivitas dan kreativitas siswa dalam kegiatan kelompok tari.

e. Hasil prestasi belajar siswa pada pembelajaran tari kelompok dinilai sangat baik. Hal ini terbukti dari jumlah 31 siswa kelas X-F1tahun ajaran 2017/2018 di SMK Negeri 7 Kota Bandung, prestasi belajar dari nilai individu maupun nilai kelompok dinyatakan tuntas.

\section{DAFTAR RUJUKAN}

Amsa, Y. S. (2018). Pengaruh Model Pembelajaran Explicit Instruction terhadap HasilBelajar pada Mata Pelajaran Akuntansi Peserta Didik Kelas XI IPS di SMA Negeri 16 Makassar. Universitas Negeri Makassar.

Anwar, A. S., \& Lapenia, P. (2019). Penerapan Model Pembelajaran Explicit Instruction untuk Meningkatkan Hasil Belajar Siswa Pokok Bahasan Cahaya dan Sifatnya pada Siswa Kelas V di SD Negeri 1 Sembawa. Jurnal Lensa Pendas, 4(1), 52-59. Retrieved from http://jurnal.upmk.ac.id/index.php/lensapendas

Arends, R., Winitzky, N. E., \& Tannenbaum, M. D. (2001). Exploring teaching : an introduction to education (Second). New York: McGraw-Hill Humanities.

Djamarah, S. B., \& Zain, A. (2013). Strategi Belajar Mengajar (Fifth). Retrieved from https://www.bukalapak. com/p/hobi-koleksi/buku/pendidikan/1oxn6s-jual-strategi-belajar-mengajar-syaiful-bahri-djamarah

Fatimah, Wartiningsih, A., \& Istiandini, W. (2014). Pengaruh Penerapan Model Pembelajaran Explicit Instruction Pada Materi Tari Serampang 12 Terhadap Hasil Belajar Siswa SMP. Jurnal Pendidikan Dan Pembelajaran Khatulistiwa, 3(8), 1-13.

Handayani, R. (2018). Pengaruh Model Pembelajaran Explicit Instruction Terhadap Hasil Belajar Siswa Pada Mata Pelajaran Sejarah Di Sekolah Menengah Atas Negeri 1 Gelumbang. Kalpataru Jurnal Sejarah Dan Pembelajaran Sejarah, 4(2), 154-161. https://doi.org/10.31851/KALPATARU.V4I2.2497

Huda, M. (2013). Model-model Pengajaran dan Pembelajaran: Isu-isu Metodis dan Paradigmatis (Second). Yogyakarta: Pustaka Pelajar.

Khoiriyah, I. (2015). Penerapan Metode Pembelajaran Explicit Instruction Untuk Meningkatkan Hasil Belajar Siswa Pada Mata Pelajaran Pemrograman Web Kelas X Jurusan Rekayasa Perangkat Lunak (RPL) Di SMK N 1 Kebumen. Universitas Negeri Semarang.

Lutfiiyah, \& Mansur. (2018). Pengaruh Model Pembelajaran Explicit Instruction Berbantuan Media Gambar Terhadap Hasil Belajar IPA. Ibtida'i, 5(10), 15-28.

Maulidar, R. (2016). Penerapan Model Pembelajaran Kooperatif Explicit Instruction Pada Materi Sistem Persamaan Linear Dua Variabel (SPLDV) Di Kelas VIII MTSS Gumpueng Pidie. Universitas Islam Negeri Ar-Raniry Darussalam - Banda Aceh.

Megawati, M. (2016). Penerapan Model Pembelajaran Explicit Instruction Untuk Meningkatkan Hasil Belajar Siswa Pada Mata Pelajaran IPA Di Kelas V SDN Ginunggung Tolitoli. Jurnal Kreatif Tadulako, 4(10). Retrieved from https://www.neliti.com/id/publications/119636/penerapan-model-pembelajaran-explicitinstruction-untuk-meningkatkan-hasil-belaj

Nurvitriawati, N., \& Sulfasyah, S. (2018). Pengaruh Model Explicit Instruction terhadap Hasil Belajar Bahasa Indonesia Membaca Konsep Denah Pada Murid Kelas IV SD. JKPD (Jurnal Kajian Pendidikan Dasar), 3(1), 417. https://doi.org/10.26618/jkpd.v3i1.1171

Oktarina, R. (2017). Pengaruh Penerapan Model Pembelajaran Explicit Instruction Terhadap Belajar Siswa Kelas IV Pada Mata Pelajaran IPA di Madrasah Ibtidaiyah Tarbiyah Islamiyah Cempaka Palembang. Universitas Islam Negeri Raden Fatah.

Primadani, H. (2011). Keefektifan Model Pembelajaran Explicit Instruction dan Picture And Picture terhadap Kemampuan Komunikasi Matematik Siswa pada Materi Pokok Lingkaran Kelas VIII SMP N 1 Karangkobar. Universitas Negeri Semarang. 
Ratunguri, Y., \& Jane, T. (2016). Penerapan Model Pembelajaran Explicit Instruction Untuk Meningkatkan Hasil Belajar Sains Pada Materi Rangka Manusia Kelas IV SD GMIM 2 Karondoran Kecamatan Ranowulu Kota Bitung. PEDAGOGIK: Jurnal Anak Usia Dini Dan Pendidikan Anak Usia Dini, 2(1), 34-40. Retrieved from http://journal.um-surabaya.ac.id/index.php/Pedagogi/article/view/28

Silma, E. (2017). Pengaruh Penerapan model Pembelajaran Explicit Instruction Terhadap Motivasi Dan Hasil Belajar Siswa Kelas XI IPS Pada Pelajaran Ekonomi (Akuntansi) Di SMAN 1 Langgam Kabupaten Pelalawan. PEKBIS (Jurnal Pendidikan Ekonomi Dan Bisnis) Jurnal, 9(1), 68-76.

Suprijono, A. (2010). Cooperative Learning, Teori dan Aplikasi PAIKEM. Retrieved from https://www.tokopedia. com/orange13/cooperative-learning-teori-aplikasi-paikem-agus-supri-murah

Suroto, S. (2015). Penggunaan Model Pembelajaran Explicit Instruction Dengan Trainer PLC Untuk Meningkatkan Prestasi Belajar Merakit Sistem PLC. Jurnal Pendidikan Teknologi Dan Kejuruan, 22(3), 316. https://doi. org/10.21831/jptk.v22i3.6838

Utari, R., Parmiti, D. P., \& Sudana, D. N. (2016). Pengaruh Model Pembelajaran Explicit Instruction Berbantuan Lingkungan Alam Sekitar Terhadap Hasil Belajar IPA Siswa Kelas IV. E-Journal PGSD Universitas Pendidikan Ganesha, 4(1), 1-10.

Yudha, P. W. D., Arsa, P. S., \& Sutaya, I. W. (2014). Penerapan Model Pembelajaran Explicit Instruction pada Praktik Pemasangan Instalasi Listrik Penerangan Bangunan Sederhana Kelas X TITL di SMK N 3 Singaraja Guna Meningkatkan Hasil Belajar Siswa. Jurnal Jurusan Pendidikan Teknik Elektro, 3(1). Retrieved from http://ejournal.undiksha.ac.id/index.php/JJPTE/article/view/4384 